\title{
Development of a new stroke scale in an emergency setting
}

\author{
Haifeng Mao', Peiyi Lin ${ }^{1}$, Junrong Mo ${ }^{1}$, Yunmei Li ${ }^{1}$, Xiaohui Chen ${ }^{1}$, Timothy H. Rainer ${ }^{2}$ and Huilin Jiang ${ }^{1 *}$
}

\begin{abstract}
Background: Early identification of stroke is crucial to maximize early management benefits in emergency departments. This study aimed to develop and validate a new stroke recognition instrument for differentiating acute stroke from stroke mimics in an emergency setting.

Methods: A prospective observational cohort study among suspected stroke patients presenting to Emergency Department in the Second Affiliated Hospital of Guangzhou Medical University was conducted from May 2012 to March 2013. The symptoms and signs of suspected stroke patients were collected. Logistic regression analysis was used to identify the factors associated with acute stroke. The symptoms and signs closely associated with acute stroke were selected to develop the new stroke scale, Guangzhou Stroke Scale (GZSS). The diagnostic value of GZSS was then compared with ROSIER, FAST and LAPSS. The primary outcome was confirmed stroke by CT within $24 \mathrm{~h}$.

Results: Four hundred and sixteen suspected stroke patients (247 ischemia, 107 hemorrhage, 4 transient ischemic attack, 58 non-stroke) were assessed. A new stroke scale, GZSS (total score from -1 to 8.5), was developed and consisted of nine parameters: vertigo $(-1), \mathrm{GCS} \leq 8(+2)$, facial paralysis $(+1)$, asymmetric arm weakness $(+1)$, asymmetric leg weakness $(+1)$, speech disturbance $(+0.5)$, visual field defect $(+1)$, systolic blood pressure $\geq 145 \mathrm{mmHg}$ $(+1)$ and diastolic blood pressure $\geq 95 \mathrm{mmHg}(+1)$. Among the four scales, the discriminatory value (C-statistic) of GZSS was the best (AUC: $0.871(p<0.001)$ when compared to ROSIER (0.772), LAPSS (0.722) and FAST (0.699). At an optimal cut-off score of $>1.5$ on a scale from -1 to 8.5 , the sensitivity and specificity of GZSS were 83.2 and $74.1 \%$, whilst the sensitivities and specificities of ROSIER were 77.7 and $70.7 \%$, FAST were 76.0 and $63.8 \%$, LAPSS were 56.4 and $87.9 \%$.
\end{abstract}

Conclusion: GZSS had better sensitivity than existing stroke scales in Chinese patients with suspected stroke. Further studies should be conducted to confirm its effectiveness in the initial differentiation of acute stroke from stroke mimics.

Keywords: Diagnosis, Stroke, Stroke mimics, ROSIER scale, FAST scale, LAPSS scale, Emergency department, China

Abbreviations: AUC, area under the ROC curve; CT, computed tomography; DWI, diffusion weighted imaging; FAST, the face arm speech test; GCS, Glasgow Coma Scale; IQR, inter quartile range; LAPSS, the Los Angeles Prehospital Stroke Screen; MRI, magnetic resonance imaging; NIHSS, National Institute of Health stroke scale; OR, odds ratio; ROC, receiver operating characteristic; ROSIER, the Recognition of Stroke in the Emergency Room scale; TIA, transient ischemic attack

\section{Background}

Stroke is one of the most common acute and severe diseases presenting to an emergency department (ED) [1]. The early assessment and management of stroke patients should reduce morbidity and mortality [1]. The use of a stroke screening tool to identify the symptoms and signs of suspected stroke and TIA increases diagnostic accuracy of

\footnotetext{
*Correspondence: lifisher@126.com

${ }^{1}$ Emergency Department, The 2nd Affiliated Hospital of Guangzhou Medical University, Guangzhou, China

Full list of author information is available at the end of the article
}

medical staff in pre-hospital and ED [1]. The widely recommended stroke scales in the western world include the Recognition of Stroke in the Emergency Room scale (ROSIER), the Face Arm Speech Test (FAST) and the Los Angeles Prehospital Stroke Screen (LAPSS). ROSIER is a seven-item ranging score from -2 to +5 that includes the clinical history (loss of consciousness, convulsive fit) and neurological signs (face, arm, or leg weakness, speech disturbance, visual field defect). FAST contains three key elements including facial weakness, arm weakness, and speech disturbance. LAPSS consists of four history items, a 
blood glucose measure, and three examination items designed to detect unilateral motor weakness [2-5]. However, our previous study demonstrated these three stroke scales were not effective for differentiating stroke from stroke mimics in Chinese settings [6, 7]. The reasons may be related to the difference in factors affecting the incidence of stroke subtypes and stroke mimic in different ethnic populations [8]. Therefore, it is necessary to develop a stroke scale suitable to a Chinese emergency setting.

The aims of our study were firstly to identify factors that predict stroke, secondly to develop a new stroke scale in our emergency setting, and thirdly to compare the diagnostic value of the new stroke scale with ROSIER, FAST and LAPSS.

\section{Methods}

\section{Study design}

A prospective observational study of patients with suspected stroke was conducted from May 2012 to March 2013. Ethical approval was obtained from the Clinical Research Ethics Committee of the 2nd Affiliated Hospital of Guangzhou Medical University. Written consents were also obtained from all patients or the closest available relatives. Patients were informed that they might withdraw from the study at any time.

\section{Study setting}

This study was conducted in the emergency department of the second Affiliated Hospital of Guangzhou Medical
University (AHGZMU), which serves a population of approximately 1.56 million people in the Hai Zhu district, Guangzhou. It is an academic hospital with 1500 beds affiliated with the Guangzhou Medical University. The ED receives more than 150,000 new patients per annum and serves a local population of approximately 1,550,000 people.

\section{Inclusion and exclusion criteria}

Suspected stroke patients $\geq 18$ years old presenting to the ED with symptoms or signs within 7 days were recruited. Patients were excluded if they were $<18$ years old, had traumatic brain injury, subarachnoid hemorrhage, or unknown diagnoses.

\section{Measurements and data collection}

Demographic data, clinical manifestations, risk factors, medical history information and the assessment of ROSIER, FAST and LAPSS were collected $[2,3]$. The final diagnosis was made by a specialist stroke physician after assessment and review of clinical symptoms and brain imaging findings (CT or MR). All the patients were divided into stroke or non-stroke groups based on the final diagnosis. Glasgow Coma Scale (GCS) was used to assess the severity of coma (the motor score was applied to the non-affected limb) [9]. All the patients' scores in this study were assessed by an emergency doctor who has obtained the certification of National Institute of Health Stroke Scale.

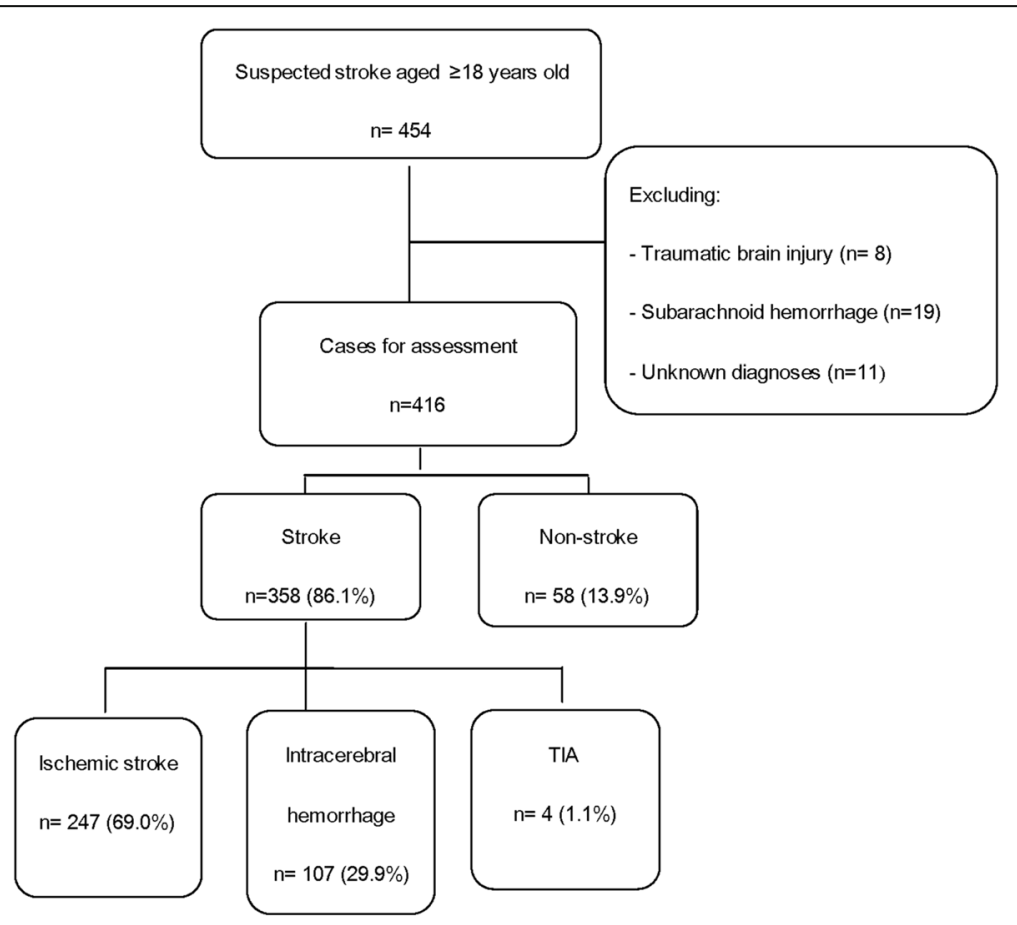

Fig. 1 Flowchart of stroke patient recruitment 


\section{Definitions}

Stroke was defined as a focal or global neurological deficit with symptoms lasting for $24 \mathrm{~h}$ or resulting in death before $24 \mathrm{~h}$, which was thought to be due to a vascular cause after investigation [3]. TIA was defined as clinical syndromes characterized by an acute loss of focal cerebral or monocular function with symptoms lasting less than $24 \mathrm{~h}$ and thought to be caused by in adequate blood supply as a result of thrombosis or embolism [3]. Vertigo is defined as the illusion of movement in space [10].

\section{Statistical analyses}

Categorical variables were compared using Chi-square analysis, whilst continuous variables were compared using independent t-tests. Univariate analysis was initially used on all variables, and results were presented as ORs with $95 \%$ CIs. Variables that were identified as significant from the univariate analysis $(p<0.05)$ were entered into logistic regression models to identify independent factors for differentiation of stroke from stroke mimics. The backward stepwise regression analyses were used to construct the models. Significant predictive

Table 1 Baseline demographic characteristics of stroke and non-stroke patients $(n=416)$

\begin{tabular}{|c|c|c|c|}
\hline Variables & Stroke $n=358$ & Non-stroke $n=58$ & $P$ \\
\hline Age & $69.2 \pm 13.8$ & $70.6 \pm 11.4$ & 0.397 \\
\hline Male, $n(\%)$ & $210(58.7)$ & $37(63.8)$ & 0.460 \\
\hline $\mathrm{SBP}, \mathrm{mmHg}$ & $168.8 \pm 31.9$ & $147.8 \pm 27.6$ & $<0.001^{*}$ \\
\hline $\mathrm{DBP}, \mathrm{mmHg}$ & $91.8 \pm 20.7$ & $80.8 \pm 14.3$ & $<0.001^{*}$ \\
\hline bpm & $80.9 \pm 18.1$ & $80.0 \pm 13.3$ & 0.742 \\
\hline \multicolumn{4}{|l|}{ Medical history, $n$ (\%) } \\
\hline Smoker & $146(40.8)$ & $20(34.5)$ & 0.339 \\
\hline Hypertension & $202(56.4)$ & $34(58.6)$ & 0.992 \\
\hline Diabetes & $58(16.2)$ & $14(24.1)$ & 0.157 \\
\hline Hyperlipidemia & $40(11.2)$ & $9(15.5)$ & 0.407 \\
\hline Ischemic heart disease & $36(10.1)$ & $8(13.8)$ & 0.434 \\
\hline Atrial fibrillation & $28(7.8)$ & $1(1.7)$ & 0.148 \\
\hline \multicolumn{4}{|l|}{ Symptoms \& signs, n (\%) } \\
\hline Asymmetric facial weakness & $181(50.6)$ & $8(13.8)$ & $<0.001^{*}$ \\
\hline Asymmetric arm weakness & 217 (60.6) & $7(12.1)$ & $<0.001^{*}$ \\
\hline Asymmetric leg weakness & $228(63.7)$ & $9(15.5)$ & $<0.001^{*}$ \\
\hline Speech disturbance & $195(54.5)$ & $17(29.3)$ & $<0.001^{*}$ \\
\hline Visual field defect & $68(19.0)$ & $1(1.7)$ & $0.001^{*}$ \\
\hline gaze palsy & $115(32.1)$ & $5(8.6)$ & $<0.001^{*}$ \\
\hline Sensory deficits & $78(21.8)$ & $8(13.8)$ & 0.163 \\
\hline Loss of consciousness or syncope & $119(33.2)$ & $10(17.2)$ & $0.015^{*}$ \\
\hline Seizure activity & $21(5.9)$ & $6(10.3)$ & 0.319 \\
\hline Pathologic reflex & $102(28.5)$ & $8(13.8)$ & $0.019^{*}$ \\
\hline Meningeal irritation & $22(6.1)$ & $0(0)$ & 0.102 \\
\hline Vertigo & $26(7.3)$ & $19(32.8)$ & $<0.001^{*}$ \\
\hline Headache & $25(7.0)$ & $3(5.2)$ & 0.816 \\
\hline Nausea & $59(16.5)$ & $26(44.8)$ & $<0.001^{*}$ \\
\hline Vomiting & $51(14.2)$ & $23(39.7)$ & $<0.001^{*}$ \\
\hline \multicolumn{4}{|l|}{ Score } \\
\hline $\mathrm{GCS}>8, n(\%)$ & $297(83)$ & $56(96.6)$ & $0.007^{*}$ \\
\hline $\mathrm{GCS} \leq 8, n(\%)$ & $61(17)$ & $2(3.4)$ & $0.007^{*}$ \\
\hline GCS, median (IQR) & $15(12-15)$ & $15(15-15)$ & $<0.001^{*}$ \\
\hline
\end{tabular}

*Statistically significant difference was observed between two groups 
variables generated in the first model were selected for the final model. The receiver operating characteristics (ROC) curve analysis was utilized to determine the optimal cutoff value of GZSS for discriminating between patients with stroke and stroke mimic. Diagnostic performances of the new stroke scale, ROSIER, FAST and LAPSS were also compared using ROC analysis. The sensitivities, specificities, positive and negative predictive values (PPV and $\mathrm{NPV}$ ), positive and negative likelihood ratios ( $\mathrm{LR}+$ and LR-), and diagnostic accuracy were calculated. Statistical significance was set at $p<0.05$. All analyses were performed using SPSS v17.0 (SPSS Inc, IL, USA) and Medcalc v9.5 (MedCalc Software, Mariakerke, Belgium).

\section{Results}

\section{Patient characteristics}

Four hundred and sixteen patients were assessed between May 2012 and March 2013. There were 358 (86.1 \%) stroke cases, including 247 (69.0\%) ischemic stroke, 107 (29.9\%) intracerebral hemorrhage, 4 (1.1 \%) TIA, and 58 (13.9 \%) non-stroke cases (Fig. 1). Compared with nonstroke group, patients with stroke had higher systolic blood pressure (SBP), diastolic blood pressure (DBP) and incidence of several symptoms and signs including asymmetric facial weakness, asymmetric arm weakness, asymmetric leg weakness, speech disturbance, visual field defect, gaze palsy, loss of consciousness or syncope and pathologic reflex (Table 1). However, non-stroke patients had higher incidence of vertigo, nausea and vomiting. The most common stroke mimics were cervical spondylosis, seizure, peripheral vertigo, which together composed $68.9 \%$ of non-stroke cases (Table 2). Among the 61 cases of stroke patients with GCS $\leq 8$, there were 47 patients with intracerebral hemorrhage (77 \%) and 14 patients with ischemia stroke (23\%), including 8 cases with total anterior circulation stroke and middle cerebral artery occlusion, 3 cases with partial anterior circulation stroke and stroke past history, 3 cases with posterior circulation stroke located in brain stem (Table 3).

\section{Development of the new stroke scale}

Logistic regression analysis of clinical symptoms and signs for stroke and non-stroke patients are shown in Table 4 . GCS $\leq 8$ was recognized as the highest prevalence, following by visual field defect, asymmetric arm weakness, asymmetric leg weakness, SBP $\geq 145 \mathrm{mmHg}$, DBP $\geq 95 \mathrm{mmHg}$, speech disturbance and vertigo. As shown in Table 5 , the items of the new stroke scale with total score from -1 to 8.5 included vertigo $(-1), \mathrm{GCS} \leq 8$ $(+2)$, Asymmetric facial weakness $(+1)$, asymmetric arm weakness $(+1)$, asymmetric leg weakness $(+1)$, speech disturbance $(+0.5)$, visual field defect $(+1), \mathrm{SBP} \geq 145 \mathrm{mmHg}$ $(+1)$, DBP $\geq 95 \mathrm{mmHg}(+1)$. We developed the new scale based on $P$ value of Multiple Logistic regression and odds ratio (Tables 4 and 5).
Table 2 Diagnoses of stroke and non-stroke patients $(n=416)$

\begin{tabular}{lc}
\hline Diagnoses & N (\%) \\
\hline Stroke classification & $358(100.0)$ \\
Total anterior circulation stroke & $41(11.5)$ \\
Partial anterior circulation stroke & $97(27.1)$ \\
Lacunar stroke & $88(24.6)$ \\
Posterior circulation stroke & $21(5.7)$ \\
Intracerebral Hemorrhage & $107(29.9)$ \\
Transient Ischemic attack & $4(1.1)$ \\
Non-stroke & $58(100.0)$ \\
cervical spondylosis & $28(48.3)$ \\
Seizure & $6(10.3)$ \\
Peripheral vertigo & $6(10.3)$ \\
Parkinson's disease & $2(3.5)$ \\
Vasovagal syncope $^{\text {Other }^{\mathrm{a}}}$ & $2(3.5)$
\end{tabular}

${ }^{\mathrm{a} O t h e r}$ diagnoses: hyponatremia and hypokalemia $(n=1)$, hypoglycemic coma $(n=1)$, alcoholic cirrhosis $(n=1)$, overdose of clozapine $(n=1)$, chronic obstructive pulmonary disease $(n=1)$, cerebral arteriosclerosis $(n=1)$, Hashimoto's encephalopathy $(n=1)$, vascular headache $(n=1)$, medulla oblongata and cervical vertebrae (C1-C2) focus $(n=1)$, scrub typhus $(n=1)$, central nervous system infection $(n=1)$, periodic paralysis $(n=1)$, facial neuritis $(n=1)$, left middle cerebral artery (M1) following stenting $(n=1)$

\section{Diagnostic performances of ROSIER, FAST, LAPSS and GZSS}

The nine-item scoring system for GZSS was constructed. Comparison of GZSS to ROSIER, FAST and LAPSS was undertaken using ROC analysis (Fig. 2). The area under curve (AUC) of GZSS was 0.871 (95 \% CI 83.5-90.2), whilst the AUC of ROSIER was 0.772 (95\% CI 72.881.1), LAPSS was 0.722 (95\% CI 67.6-74.6) and FAST was 0.699 (95\% CI 65.2-74.3). By pairwise comparison of the AUC of the four scales (adjusted $\alpha=0.008$ ), the comparison was statistically significant $(p<0.001)$. Among the four scales, the diagnostic value of GZSS was the best (Fig. 2).

The optimal cut-off score of GZSS was determined to be a total score of 1.5. At this cut-off score, the corresponding sensitivity and specificity were $83.2 \%$ (95\% CI 79.0-87.0) and 74.1 \% (95 \% CI 61.0-84.7). The sensitivity and specificity of ROSIER scale were $77.7 \%$ (95 \% CI 73.0-81.9) and $70.7 \%$ (95\% CI 57.3-81.9) when the

Table 3 The subtype of stroke patients with GCS $\leq 8$

\begin{tabular}{ll}
\hline Diagnoses & $N(\%)$ \\
\hline Intracerebral Hemorrhage & $47(77.0)$ \\
Ischemia stroke & $14(23.0)$ \\
Total anterior circulation stroke & 8 \\
Partial anterior circulation stroke & 3 \\
Posterior circulation stroke & 3 \\
Total & $61(100.0)$ \\
\hline
\end{tabular}


Table 4 Factors associated with stroke using logistic regression analysis

\begin{tabular}{|c|c|c|c|c|c|}
\hline \multirow[t]{2}{*}{ Variables } & \multirow[b]{2}{*}{$N(\%)$} & \multicolumn{2}{|c|}{ Univariate regression } & \multicolumn{2}{|c|}{ Multivariate regression } \\
\hline & & OR $(95 \% \mathrm{Cl})$ & $P$ & OR (95 \% Cl) & $P$ \\
\hline Female & $169(40.6)$ & 1 & & & \\
\hline Male & $247(59.4)$ & $0.81(0.45-1.43)$ & 0.461 & & \\
\hline Age & & $0.99(0.97-1.01)$ & 0.457 & & \\
\hline GCS $>8$ & $353(84.9)$ & 1 & & & \\
\hline $\mathrm{GCS} \leq 8$ & $63(15.1)$ & $5.75(1.37-24.20)$ & $0.017^{*}$ & $5.70(1.26-25.80)$ & $0.024^{*}$ \\
\hline \multicolumn{6}{|c|}{ Seizure activity } \\
\hline NO & $389(93.5)$ & 1 & & & \\
\hline YES & $27(6.5)$ & $0.54(0.21-0.54)$ & 0.205 & & \\
\hline \multicolumn{6}{|l|}{ Vertigo } \\
\hline NO & $371(89.1)$ & 1 & & & \\
\hline YES & $45(10.8)$ & $0.16(0.08-0.32)$ & $<0.001^{*}$ & $0.34(0.15-0.74)$ & $0.007^{*}$ \\
\hline \multicolumn{6}{|c|}{ Asymmetric facial weakness } \\
\hline NO & $227(54.6)$ & 1 & & & \\
\hline YES & $189(45.4)$ & $6.39(2.95-13.87)$ & $<0.001^{*}$ & $2.44(0.97-6.11)$ & 0.057 \\
\hline \multicolumn{6}{|c|}{ Asymmetric arm weakness } \\
\hline NO & $192(46.2)$ & 1 & & & \\
\hline YES & $224(53.8)$ & $11.21(4.95-25.41)$ & $<0.001^{*}$ & $3.39(1.04-11.08)$ & $0.043^{*}$ \\
\hline \multicolumn{6}{|c|}{ Asymmetric leg weakness } \\
\hline NO & $179(43.0)$ & 1 & & & \\
\hline YES & $237(57.0)$ & $9.55(4.54-20.07)$ & $<0.001^{*}$ & $2.77(0.88-8.70)$ & 0.081 \\
\hline \multicolumn{6}{|c|}{ Speech disturbance } \\
\hline NO & $204(49.0)$ & 1 & & & \\
\hline YES & $212(51.0)$ & $2.89(1.58-5.27)$ & $0.001^{*}$ & $1.29(0.58-2.84)$ & 0.524 \\
\hline \multicolumn{6}{|c|}{ Visual field defect } \\
\hline NO & $347(83.4)$ & 1 & & & \\
\hline YES & 69 (16.6) & 13.37 (1.82-98.23) & $0.011^{*}$ & $3.93(0.48-32.30)$ & 0.202 \\
\hline \multicolumn{6}{|c|}{ Gaze palsy } \\
\hline NO & $296(71.2)$ & 1 & & & \\
\hline YES & $120(28.8)$ & $5.02(1.95-12.89)$ & $0.001^{*}$ & $0.75(0.19-3.08)$ & 0.693 \\
\hline \multicolumn{6}{|c|}{ Pathologic reflex } \\
\hline NO & $306(73.6)$ & 1 & & & \\
\hline YES & $110(26.4)$ & $2.49(1.14-5.44)$ & $0.022^{*}$ & $0.73(0.28-1.91)$ & 0.516 \\
\hline \multicolumn{6}{|c|}{$\mathrm{SBP} \geq 145 \mathrm{mmHg}$} \\
\hline NO & $111(26.7)$ & 1 & & & \\
\hline YES & $305(73.3)$ & $3.99(2.25-7.07)$ & $<0.001^{*}$ & $2.55(1.25-5.24)$ & $0.011^{*}$ \\
\hline \multicolumn{6}{|c|}{$\mathrm{DBP} \geq 95 \mathrm{mmHg}$} \\
\hline NO & $270(64.9)$ & 1 & & & \\
\hline YES & $146(35.1)$ & $4.62(2.04-10.48)$ & $<0.001^{*}$ & $2.29(0.87-6.03)$ & 0.093 \\
\hline
\end{tabular}

*Statistically significant $(p<0.05)$

optimal cut-off score was 0 . The sensitivity and specificity of FAST scale were $76.0 \%$ (95 \% CI 71.2-80.3) and $63.8 \%$ (95 \% CI 50.1-76.0) when the optimal cut-off score was 0 . The sensitivity and specificity of LAPSS scale were $56.4 \%$ (95 \% CI 51.1-61.6) and $87.9 \%$ (95\% CI 76.7-95.0) when the optimal cut-off score was 0 . The sensitivity of GZSS was the best and was significantly different from the sensitivities of ROSIER scale $(p=$ 
Table 5 Clinical signs and symptoms for development of the new stroke scale

\begin{tabular}{lllll}
\hline Variables & Score & $\beta$ & OR $(95 \% \mathrm{Cl})$ & $P$ value \\
\hline Vertigo & -1 & -1.09 & $0.34(0.15-0.74)$ & $0.007^{*}$ \\
GCS $\leq 8$ & 2 & 1.74 & $5.70(1.26-25.80)$ & $0.024^{*}$ \\
Asymmetric facial weakness & 1 & 0.89 & $2.44(0.97-6.11)$ & 0.057 \\
Asymmetric arm weakness & 1 & 1.22 & $3.39(1.04-11.08)$ & $0.043^{*}$ \\
Asymmetric leg weakness & 1 & 1.02 & $2.77(0.88-8.70)$ & 0.081 \\
Speech disturbance & 0.5 & 0.26 & $1.29(0.58-2.84)$ & 0.524 \\
Visual field defect & 1 & 1.37 & $3.93(0.48-32.30)$ & 0.202 \\
SBP $\geq 145 \mathrm{mmHg}$ & 1 & 0.94 & $2.55(1.25-5.24)$ & $0.011^{*}$ \\
DBP $\geq 95 \mathrm{mmHg}$ & 1 & 0.83 & $2.29(0.87-6.03)$ & 0.093 \\
\hline
\end{tabular}

$* P<0.05$

Stroke is likely if total scores are $>1.5$

$0.031)$, FAST scale $(p=0.004)$ and LAPSS scale $(p<$ 0.001) (Table 6).

\section{Discussion}

This was the first study to develop a new stroke scale in China. In recent years, the incidence of stroke is still rising year by year around the world and its high morbidity

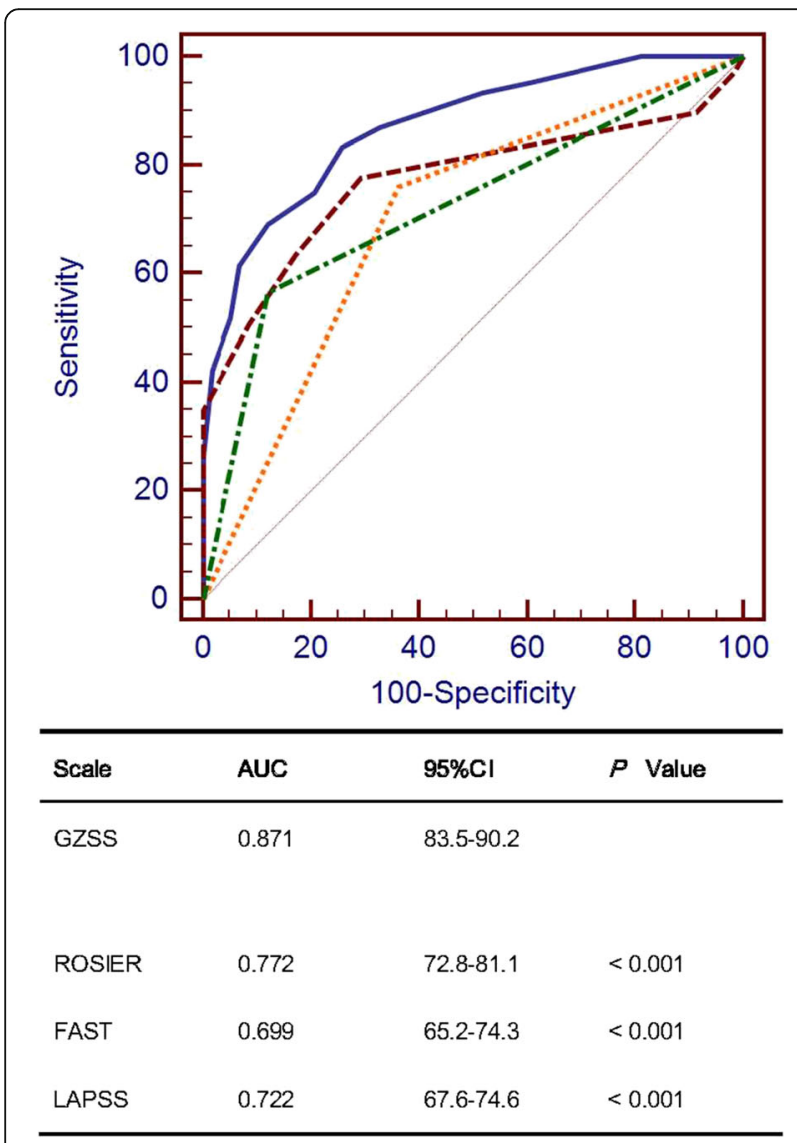

Fig. 2 Receiver operating characteristic ROC curves of GZSS, ROSIER, FAST and LAPSS in differentiation of stroke and non-stroke patients can cause serious social and family burden [11-14]. Early recognition and timely treatment of patients with acute stroke by emergency physicians are critical and improve the prognosis of stroke patients [15-22]. Stroke screening scales were recommended by guidelines in pre-hospital and emergency room for rapid triage of suspected patients [1, 3, 23-25].

In this study, we found that there were significant differences in the distribution of stroke subtypes between the patients in our study and the Western patients in the studies using other scales. There was a higher proportion of intracerebral haemorrhage in our study compared with the other Western studies [26-29]. Also, there were less ischaemic stroke (69 versus $76 \%$ ) and TIA (1.1 versus $10 \%)$, but more haemorrhagic stroke (29.9 versus $14 \%$ ) in our study than in the ROSIER study [2]. These differences in subtype patterns are postulated to be due to differences in genetic, clinical, environmental and lifestyle factors $[8,30,31]$. There were also differences in the proportion of stroke mimics between this study and the other Western studies, Seizures $(10.3 \%)$ and syncope $(17.2 \%)$ in Guangzhou were less common than in the UK (47 \%) [2]. Another UK study found that primary headache disorders and seizures comprised up to $27 \%$ of stroke mimics [32], whilst in Greece [33] the principal stroke mimics were aphasic disturbances (27.3\%) and dizziness or fainting (27.3\%).

We analyzed different clinical features of stroke in our ED and thus developed a new stroke recognition instrument (score range: -1 to 8.5 ), which consisted of nine items including vertigo $(-1), \mathrm{GCS} \leq 8(+2)$, facial paralysis $(+1)$, asymmetric upper limb paralysis $(+1)$, asymmetric lower limb paralysis $(+1)$, speech disorders $(+0.5)$, visual field defect $(+1)$, SBP $\geq 145 \mathrm{mmHg}(+1)$, DBP $\geq 95 \mathrm{mmHg}(+1)$. The new stroke scale showed good discriminative value in our ED.

In GZSS, five recognition items were the same as in ROSIER scale, FAST score and LAPSS. These items with different odds ratios were included in the new stroke scale, such as asymmetric facial weakness (OR: 6.39), asymmetric arm weakness (OR: 11.21), asymmetric leg weakness (OR: 9.55), speech disturbance (OR: 2.89), visual field defect (OR: 13.37). We assigned the corresponding score to each item of the new scale based on the logistic regression coefficients.

There were some new items added in GZSS based on the analysis. In our previous study, we found that the level of consciousness of patients may affect the diagnostic value of the stroke screening scales $[2,6,7]$. Therefore, we assessed the diagnostic value of GCS in patients with suspected stroke. We found that GCS equal or less than 8 points (OR: 5.75 ) was associated with the diagnosis of stroke. Stroke patients often have disturbance of consciousness and are unable to cooperate in medical 
Table 6 Diagnostic performance of ROSIER, FAST, LAPSS and GZSS

\begin{tabular}{|c|c|c|c|c|c|c|c|c|c|c|}
\hline Scale & Optimal cut-off & Sensitivity $(95 \% \mathrm{Cl}$ ) & $P$ & Specificity (95 \% Cl) & $P$ & PLR $(95 \%$ CI) & NLR $(95 \% \mathrm{Cl})$ & PPV $(95 \%$ Cl) & NPV $(95 \%$ Cl) & Diagnostic accuracy (\%) \\
\hline ROSIER & 0 & 77.7 (73.0-81.9) & 0.031 & 70.7 (57.3-81.9) & 0.754 & $2.65(1.8-4.0)$ & $0.32(0.2-0.4)$ & $94.2(90.9-96.6)$ & $33.9(25.5-43.1)$ & 76.68 \\
\hline FAST & 0 & $76.0(71.2-80.3)$ & 0.004 & $63.8(50.1-76.0)$ & 0.210 & $2.1(1.5-3.0)$ & $0.38(0.3-0.5)$ & $92.8(89.2-95.5)$ & $30.1(22.1-39.0)$ & 74.28 \\
\hline LAPSS & 0 & $56.4(51.1-61.6)$ & $<0.001$ & $87.9(76.7-95.0)$ & 0.008 & $4.68(2.3-9.4)$ & $0.50(0.4-0.6)$ & 96.7 (93.2-98.6) & $24.6(18.9-31.1)$ & 60.82 \\
\hline GZSS & 1.5 & $83.2(79.0-87.0)$ & Reference & $74.1(61.0-84.7)$ & Reference & $3.22(2.1-5.0)$ & $0.23(0.2-0.3)$ & $95.2(92.2-97.3)$ & $41.7(32.1-51.9)$ & 81.97 \\
\hline
\end{tabular}

ROSIER Recognition of Stroke in the Emergency Room scale, FAST Face Arm Speech Test, LAPSS Los Angeles Pre-Hospital Stroke Screen, GZSS Guangzhou Stroke Scale, PLR positive likelihood ratio, NLR negative likelihood ratio, $P P V$ positive predictive value, $N P V$ negative predictive value 
examinations. It would be difficult for coma patients to carry out some of the physical examinations, such as paralysis and speech disorders. In this case, most of the stroke screening scales developed in western countries, such as FAST and LAPSS, cannot be applied to stroke patients with loss of consciousness. Also, if stroke patients present with loss of consciousness and do not have paralysis and speech disorders, the total score of ROSIER scale is equal to or less than 0 and thus means stroke is not likely to occur. This would easily lead to false negative. Therefore, we included GCS in GZSS to compensate the deficiency of the other stroke scales.

Vertigo was another new item in GZSS. Our study suggested vertigo occurred more often in Chinese nonstroke population than Western population. In the western population, the proportion of stroke and non-stroke patients with vertigo were similar (6 and $5 \%$, respectively) [2]. However, $58.6 \%$ of patients had cervical spondylosis and peripheral vertigo in this study. By logistic regression analysis, the regression coefficient $\beta$ of vertigo was negative, which suggested that vertigo was a differential symptom between stroke and non-stroke patients.

In addition, our new scale included SBP and DBP. We used ROC analysis to determine the optimal cut-off values of SBP ( $\geq 145 \mathrm{mmHg}$ ) and DBP $(\geq 95 \mathrm{mmHg})$. By logistic regression analysis, we found that the OR of SBP and DBP were2.55 and 2.29, respectively. When acute stroke occurs, SBP and DBP are higher than usual. Blood pressure of more than $80 \%$ of patients increased within 24 to $48 \mathrm{~h}$ after the onset of cerebral ischemic, and declined gradually in a few days or several weeks. One of the reasons might be due to the regulation disorder of cerebral blood flow in ischemic penumbra [34, 35]. Patients with hemorrhagic stroke experienced increased intracranial pressure, and thus the blood pressure would increase to maintain the normal cerebral blood flow. In this study, the blood pressure was higher in patients with stroke than non-stroke $(p<0.01)$. Also, 392 patients $(94.2 \%)$ including 337 stroke patients $(81.0 \%)$ and 55 non-stroke patients $(13.2 \%)$ presented to ED within $24 \mathrm{~h}$ after symptom onset. Only $5.8 \%$ of patients presented over $24 \mathrm{~h}$ after symptom onset. This indicated that the vast majority of patients with suspected stroke in our study were in acute period of cerebral apoplexy. Therefore, blood pressure also played a significant role in the diagnosis of patients with suspected stroke in the emergency department.

A comparison of the new stroke scale with the other three scales (ROSIER scale, FAST scale and LAPSS scale) was conducted in our ED. We found that the new scale had better sensitivity than the other scales. The AUC of GZSS was the largest $(\mathrm{AUC}=0.871)$. At the optimal cutoff score of 1.5, GZSS gave high sensitivity and comparable specificity. It may be more effective to use GZSS to screen Chinese patients with suspected stroke in ED.

\section{Limitations}

There were several limitations in this study. First, this study was a single-center study. Our results may not be generalizable to other parts of China, let alone elsewhere in the world. Multicenter studies with larger sample sizes are needed to explore the effectiveness of this new stroke scale. Second, using GCS in GZSS may not be appropriate in all circumstances. A patient who has had a stroke may be aphasic and hemiplegic. They may be fully conscious but only scored E4V1M6 giving them a GCS of $11 / 15$, which is clearly misleading. It may be necessary to break down the GCS into the component parts (i.e. E4V1M6 instead of GCS 9) to get much more information. Third, it would have been stronger to have separate derivation and validation datasets rather than a single dataset. Therefore, further studies with larger sample sizes are required to validate the effectiveness of GZSS and improve its weakness.

\section{Conclusion}

GZSS had better sensitivity than the existing stroke scales in Chinese patients with suspected stroke. Further studies are required to validate its usefulness in the initial differentiation of acute stroke from stroke mimics.

\section{Acknowledgements \\ This research study was supported by the Key Medical Disciplines and Specialties Program of Guangzhou and the Guangzhou City Health Bureau (Grant No.20141A011084). \\ Funding \\ This research study was supported by the Key Medical Disciplines and Specialties Program of Guangzhou and the Guangzhou City Health Bureau (Grant No.20141A011084).}

\section{Availability of data and materials}

The datasets during and/or analysed during the current study available from the corresponding author on reasonable request.

\section{Authors' contributions}

$\mathrm{HJ}, \mathrm{HM}$ and PL designed the study and undertook the statistical analysis. HM $J M$ and $Y L$ were involved in collecting data. $\mathrm{HJ}$ and $\mathrm{HM}$ drafted the manuscript. XC and THR contributed to manuscript revision. The corresponding author $\mathrm{HJ}$ supervised the whole study. All authors have read and approved the final manuscript.

\section{Competing interests}

The authors declare that they have no competing interests.

Consent for publication

Not applicable.

Ethics approval and consent to participate

Ethical approval was obtained from the Clinical Research Ethics Committee of the 2nd Affiliated Hospital of Guangzhou Medical University. Written consents were also obtained from all patients or the closest available relatives. Patients were informed that they might withdraw from the study at any time.

\section{Author details}

'Emergency Department, The 2nd Affiliated Hospital of Guangzhou Medical University, Guangzhou, China. Institute of Molecular and Experimental Medicine, Welsh Heart Research Institute, Cardiff University School of Medicine, Cardiff, UK. 
Received: 7 December 2015 Accepted: 3 September 2016 Published online: 08 September 2016

\section{References}

1. Jauch EC, Saver JL, Adams HP, Bruno A, Connors JJ, Demaerschalk BM, et al. Guidelines for the early management of patients with acute ischemic stroke: a guideline for healthcare professionals from the American Heart Association/American Stroke Association. Stroke. 2013;44:870-947.

2. Nor AM, Davis J, Sen B, Shipsey D, Louw SJ, Dyker AG, et al. The Recognition of Stroke in the Emergency Room (ROSIER) scale: development and validation of a stroke recognition instrument. Lancet Neurol. 2005;4: 727-34.

3. Harbison J, Hossain O, Jenkinson D, Davis J, Louw SJ, Ford GA. Diagnostic accuracy of stroke referrals from primary care, emergency room physicians, and ambulance staff using the face arm speech test. Stroke. 2003;34:71-6.

4. Kidwell CS, Starkman S, Eckstein M, Weems K, Saver JL. Identifying stroke in the field. Prospective validation of the Los Angeles prehospital stroke screen (LAPSS). Stroke. 2000;31:71-6.

5. Kidwell CS, Saver JL, Schubert GB, Eckstein M, Starkman S. Design and retrospective analysis of the Los Angeles Prehospital Stroke Screen (LAPSS). Prehosp Emerg Care. 1998;2:267-73.

6. Jiang HL, Chan CP, Leung YK, Li YM, Graham CA, Rainer TH. Evaluation of the Recognition of Stroke in the Emergency Room (ROSIER) scale in Chinese patients in Hong Kong. PLoS One. 2014;9:e109762.

7. Chen XH, Mao HF, Mo JR, Lin PY, Tian CW, Zhang Y, et al. Validation of three different stroke screen scales in an Emergency setting. Chinese Journal of Critical Care Medicine. 2013;33:539-42.

8. Zhang LF, Yang J, Hong Z, Yuan GG, Zhou BF, Zhao LC, et al. Proportion of different subtypes of stroke in China. Stroke. 2003;34:2091-6.

9. Ling G. Traumatic brain injury and spinal cord injury. In: Goldman L, Schafer Al, editors. Goldman's Cecil medicine. 24th ed. Singapore: Elsevier; 2012. p. 2253.

10. Baloh RW, Jen J. Hearing and equilibrium. In: Goldman L, Schafer Al, editors. Goldman's Cecil medicine. 24th ed. Singapore: Elsevier; 2012. p. 2465.

11. Murray CJ, Vos T, Lozano R, Naghavi M, Flaxman AD, Michaud C, et al. Disability-adjusted life years (DALYs) for 291 diseases and injuries in 21 regions, 1990-2010: a systematic analysis for the Global Burden of Disease Study 2010. Lancet. 2012;380:2197-223.

12. Norrving B, Kissela B. The global burden of stroke and need for a continuum of care. Neurology. 2013;80:S5-S12.

13. Johnston SC, Mendis S, Mathers CD. Global variation in stroke burden and mortality: estimates from monitoring, surveillance, and modelling. Lancet Neurol. 2009;8:345-54.

14. Hu XL, Gong XG. The economic burden of ischemic stroke in China. China Healthcare Economy. 2003;22:18-20.

15. Hacke W, Kaste M, Bluhmki E, Brozman M, Dávalos A, Guidetti D, et al. Thrombolysis with alteplase 3 to 4.5 hours after acute ischemic stroke. N Engl J Med. 2008:359:1317-29.

16. Sandercock P, Wardlaw JM, Lindley RI, Dennis M, Cohen G, Murray G, et al. The benefits and harms of intravenous thrombolysis with recombinant tissue plasminogen activator within $6 \mathrm{~h}$ of acute ischaemic stroke (the third international stroke trial [IST-3]): a randomised controlled trial. Lancet. 2012; 379:2352-63.

17. Morgenstern LB, Hemphill 3rd JC, Anderson C, Becker K, Broderick JP, Connolly Jr ES, et al. Guidelines for the management of spontaneous intracerebral hemorrhage: a guideline for healthcare professionals from the American Heart Association/American Stroke Association. Stroke. 2010;41: 2108-29.

18. Shah KH, Kleckner K, Edlow JA. Short-term prognosis of stroke among patients diagnosed in the emergency department with a transient ischemic attack. Ann Emerg Med. 2008:51:316-23.

19. Hacke W, Donnan G, Fieschi C, Kaste M, von Kummer R, Broderick JP, et al. Association of outcome with early stroke treatment: pooled analysis of ATLANTIS, ECASS, and NINDS rt-PA stroke trials. Lancet. 2004;363:768-74.

20. Marler JR, Tilley BC, Lu M, Brott TG, Lyden PC, Grotta JC, et al. Early stroke treatment associated with better outcome: the NINDS rt-PA stroke study. Neurology. 2000;55:1649-55.

21. Moon JS, Janjua N, Ahmed S, Kirmani JF, Harris-Lane P, Jacob M, et al. Prehospital neurologic deterioration in patients with intracerebral hemorrhage. Crit Care Med. 2008;36:172-5.
22. Brott T, Broderick J, Kothari R, Barsan W, Tomsick T, Sauerbeck L, et al Early hemorrhage growth in patients with intracerebral hemorrhage. Stroke. 1997;28:1-5

23. Azzimondi G, Bassein L, Fiorani L, Nonino F, Montaguti U, Celin D, et al. Variables associated with hospital arrival time after stroke: effect of delay on the clinical efficiency of early treatment. Stroke. 1997;28:537-42.

24. Ferro JM, Pinto AN, Falcao I, Rodrigues G, Ferreira J, Falcão F, et al. Diagnosis of stroke by the nonneurologist. A validation study. Stroke. 1998;29:1106-9.

25. Moulin T, Sablot D, Vidry E, Belahsen F, Berger E, Lemounaud P, et al. Impact of emergency room neurologists on patient management and outcome. Eur Neurol. 2003;50:207-14.

26. Islam MS, Anderson CS, Hankey GJ, Hardie K, Carter K, Broadhurst R, et al. Trends in incidence and outcome of stroke in Perth, Western Australia during 1989 to 2001: the Perth Community Stroke Study. Stroke. 2008;39: 776-82.

27. Béjot Y, Aouba A, de Peretti C, Grimaud O, Aboa-Eboulé C, Chin F, et al. Time trends in hospital-referred stroke and transient ischemic attack: result of a 7-year nationwide survey in France. Cerebrovasc Dis. 2010;30:346-54.

28. Corso G, Bottacchi E, Giardini G, De la Pierre F, Meloni T, Pesenti Campagnoni $\mathrm{M}$, et al. Community-based study of stroke incidence in the Valley of Aosta, Italy. Neuroepidemiology. 2009;32:186-95.

29. Tsai CF, Thomas B, Sudlow CL. Epidemiology of stroke and its subtypes in Chinese vs white populations. Neurology. 2013;81:264-72.

30. Jiang B, Wang WZ, Chen H, Hong Z, Yang QD, Wu SP, et al. Incidence and trends of stroke and its subtypes in China:results from three large cities. Stroke. 2006:37:63-8.

31. Feigin VL, Lawes CM, Bennett DA, Anderson CS. Stroke epidemiology: a review of population-based studies of incidence, prevalence, and case-fatality in the late 20th century. Lancet Neurol. 2003;2:43-53.

32. Whiteley WN, Wardlaw JM, Dennis MS, Sandercock PA. Clinical scores for the identification of stroke and transient ischaemic attack in the emergency department: a cross-sectional study. J Neurol Neurosurg Psychiatry. 2011:82:1006-10.

33. Hatzitolios A, Savopoulos C, Ntaios G, Papadidaskalou F, Dimitrakoudi E, Kosmidou $\mathrm{M}$, et al. Stroke and conditions that mimic it: a protocol secures a safe early recognition. Hippokratia. 2008;12:98-102.

34. Bath P, Chalmers J, Powers W, Beilin L, Davis S, Lenfant C, et al. International Society of Hypertension (ISH): statement on the management of blood pressure in acute stroke. J Hypertens. 2003;21:665-72.

35. Blood pressure, cholesterol, and stroke in eastern Asia. Eastern Stroke and Coronary Heart Disease Collaborative Research Group. Lancet. 1998; 352:1801-7.

\section{Submit your next manuscript to BioMed Central and we will help you at every step:}

- We accept pre-submission inquiries

- Our selector tool helps you to find the most relevant journal

- We provide round the clock customer support

- Convenient online submission

- Thorough peer review

- Inclusion in PubMed and all major indexing services

- Maximum visibility for your research

Submit your manuscript at www.biomedcentral.com/submit
Biomed Central 